\title{
A review of the impact of noise restrictions at airports
}

\author{
A. Rodríguez-Díaz, B. Adenso-Díaz, P.L. González-Torre ${ }^{\mathrm{b}}$ \\ ${ }^{\text {a }}$ INDRA, Air Traffic Control \\ ${ }^{\mathrm{b}}$ Escuela Politécnica de Ingeniería de Gijón, Universidad de Oviedo, Spain \\ Corresponding author: amrodriguezd@indra.es \\ Phone: +34636 677917 \\ A. Rodríguez-Díaz, B. Adenso-Diaz, P. González-Torre (2017) “A review of the impact \\ of noise restrictions at airports", TRANSPORTATION RESEARCH-D, 50, 1, 144-153
}

\begin{abstract}
$\underline{\text { Abstract }}$
One of the biggest obstacles to the building of new airports and expanding runway capacity is environmental concerns, especially noise. In this paper, we review what has been previously studied in the literature concerning the noise reduction problem around airports from the Air Traffic Control (ATC) perspective. In order to facilitate the knowledge of the current situation, a regulation summary from the USA and EU is provided. We mainly focus our research on operational procedures, since they are one of the easiest improvements nowadays for reducing the impact of noise around airports. Moreover, the paper sums up the modelling, monitoring and simulation tools related to noise at airports proposed in the literature. Finally, special care is taken to review the optimization tools, the objective of which is to take into account the noise problem in order to help, or propose alternatives, to reduce its impact from airport operations.
\end{abstract}

Keywords: air traffic growth, airport capacity, noise impact, procedures, optimization. 


\section{INTRODUCTION}

Airbus's Global Market Forecast 2015-2034 highlights that today, 47 aviation megacities are focused on over $90 \%$ of long-haul flights and nearly a million passengers a day, with 39 of the 47 experiencing various levels of congestion (Airbus, 2014). Demand is being met through more of the latest technology aircraft, and by airlines striving to increase their efficiency by filling every available seat, with average load factors now close to an impressive $80 \%$. Air traffic demand is expected to more than double in Europe and the US, and perhaps triple in some regions, over the next 15 years (Airbus, 2014). Therefore, one of the central challenges facing the aviation industry is air traffic demand growth, which results in congestion in many airports, primarily hubs (Flores-Fillol, 2010).

Meeting this increased demand is challenging for all the industry stakeholders. Airlines around the world have responded by developing their networks and using larger aircraft. Building new airports and expanding the runway capacity of existing ones is another possible solution, but limited by environmental concerns, including noise disturbance, emissions, water pollution and habitat destruction (Laurenzo, 2006). Some impacts arise from the operation of the airport, others as a result of providing additional airport infrastructure (Upham et al., 2003). Making the most efficient use of the current infrastructure by Air Traffic Management (ATM) would be the best alternative to balance demand and runway capacity with environmental restrictions.

Aircraft noise is a particular problem during landing and take-off (Ignaccolo, 2000). Noise, described as unwanted sound (Schmidt, 2005), is known to have several adverse effects on humans, such as hearing loss, communication interference, sleep interference, higher levels of self-reported stress, anxiety, depression, psychological morbidity, 
annoyance, hypertension and coronary heart disease (Janssen et al., 2014; Salah, 2014; Ozkurt et al., 2014; Vogiatzis, 2012). Ongoing technological advances are likely to result in quieter engines, and aircraft operating from short and underutilized runways (Schneider et al., 2010). Other options that are in use today are sound insulation of buildings or land use procedures (Ganic et al., 2015). However, in order to reconcile system resource constraints with economic and environmental priorities, all the involved stakeholders (governments, aircraft manufacturers, ATC) are requested to collaborate (Bertsimas et al., 2011).

The objective of this paper is to review how airport capacity is limited by noise restrictions, with the aim of analysing the potentiality of using scheduling optimization tools in order to confront the problem. Analysing what measures are being taken today to deal with noise reduction and what can be improved from the ATC point of view, focusing on operational alternatives and models, might be interesting in order to have a starting point to understand the problem. To facilitate knowledge of the current situation about noise restrictions, a regulation summary is provided. Operational procedures are also reviewed since they are one of the easiest improvements today for reducing the impact of noise in the areas surrounding airports without impacting on airport capacity. Moreover, the paper sums up the modelling, monitoring and simulation tools related to noise in airports, that exist in the literature, since a review of this field has not been found so far and it is necessary to understand how noise impact is calculated. Finally, as already mentioned, special care is taken to review optimization tools that take into account the noise problem in order to help, or propose alternatives, to reduce it and how this impacts on airport capacity.

This paper is organized as follows. Section 2 provides a description of the methodology 
followed. Sections 3 and 4 describe the environmental issues concerning air traffic growth. Section 5 provides a review of the legislation, mainly from USA and Europe. Section 6 analyses another way of minimizing noise, though noise abatement operational procedures. Section 7 describes the different modelling, monitoring and simulation tools found in the literature referring to noise around airports. Section 8 deals with optimization tools and algorithms that take into account noise restrictions. Finally, a short summary is given in Section 9, together with suggested topics for future research in this area.

\section{REVIEW METHODOLOGY}

A literature review is useful to provide a historical perspective of the respective research area as well as a benchmark for comparing the results with other findings (Creswell, 2013). In our case we have applied a Systematic Literature Review (SLR) (Denyer and Tranfield, 2009) consisting of five steps. The first is the definition of the context, intervention, mechanisms and outcome (CIMO) of the study. In our case, this is studying how noise reduction has impacted on runway capacity from an operations point of view.

The next two steps in an SLR are the location of studies, and their selection and evaluation. Here, the literature search was carried out through the Scopus database. We considered also conference papers and documentation from international organisations (such as ICAO, SESAR, FAA) since the subject under research is of a wide scope, and official reports could add something to the study. Regarding the time horizon, we have not limited it, but all the papers found that focus on the impact of noise were from 1998 
until 2016. The keywords used are: \{“airport capacity" OR "scheduling” OR "procedures" OR “optimization"\} AND \{“noise reduction" OR "aircraft noise"\}.

After a first scrutiny, some of the collected papers were discarded because they did not fit exactly the theme of the review study, leaving a total of 131 papers or official documentation. We found a large amount of papers related to noise influence on health or sound insulation that were discarded since these topics are not related to runway capacity.

The last two steps are the analysis and synthesis of the papers, and to report and use the results, which we cover in the following sections.

\section{ENVIRONMENTAL CHALLENGES IN AIRPORTS}

The aviation industry understands that environmental responsibility is a critical component of its licence to grow. Aviation was the first sector in the world to agree to an ambitious set of global carbon dioxide $\left(\mathrm{CO}_{2}\right)$ emissions-reduction targets, which include carbon neutral growth from 2020 and a 50\% reduction in net $\mathrm{CO}_{2}$ emissions by 2050 compared to 2005 levels (ICAO, 2013). Aviation stakeholders have committed to achieve these through a four-pillar strategy including improved technology, more efficient infrastructure, and better operations.

Environmental assessment (evaluation and review, research and monitoring), environmental management (comprehensive planning that takes into account the effects of humankind's activities on the environment) and supporting measures (education, training, public information, financial assistance and organizational arrangements), are key in any approach towards successful environmental management (Abeyratne, 2002).

According to Single European Sky ATM Research (SESAR), the two main 
environmental issues associated with aviation are emissions and noise (SESAR, 2016). On the other hand, according to the Next Generation Air Transportation System (NextGen), the primary environmental issues that influence the capacity and flexibility of the National Airspace System (NAS) are aircraft noise, air quality, climate, energy, and water quality (Hughes et al., 2012). Both NextGen and SESAR agree therefore on two objectives: emissions and noise (Table 1).

------ Table 1 ------

Global emissions are related to climate change since aircraft emit gases and particles in direct proportion to the quantity of fuel burned directly into the upper troposphere and lower stratosphere; $\mathrm{CO}_{2}$ is also emitted at airports through various airport operations, such as ground support vehicles and passenger surface transport vehicles. Globally, the aviation industry accounts for around $2 \%$ of all human-induced $\mathrm{CO}_{2}$ emissions (ATAG, 2014).

Local emissions refer to aircraft operations at airports (landing and taking off, taxiing, fuel storage, engine testing and the use of auxiliary power units) that impact on local air quality through pollutants emitted during these operations. Additionally, other airport operations, such as the use of ground support equipment, airport air-conditioning, passenger cars, and many others, also affect local air quality.

Generally aircraft noise is influenced by particular factors such as the number of flights, their timing, the type of aircraft, and the flight path. Aircraft noise is a disturbance produced by any aircraft or its components, during flight, taxiing, landing and take-off. Sari et al. (2014) classify the origins of this noise into three main sources: the aerodynamic noise, the aircraft engine and other mechanical sources, while Arntzen \& Simons (2014) classify aircraft noise into two categories: engine noise and airframe 
noise.

\section{REDUCING THE IMPACT OF NOISE IN AIRPORT SURROUNDINGS}

One of the reasons for an increase in the number of people affected by negative noise is the rise of populations in cities and their territorial expansion, since residential areas have become closer to airports (Ganic et al., 2015). Reducing the environmental impact of growing traffic demand leads to severe problems for balancing airport expansion requirements (Arntzen \& Simons, 2014; Visser et al., 2008).

In 2001, the International Civil Aviation Organization (ICAO, 2001) Assembly endorsed the concept of a Balanced Approach to aircraft noise management, which was reaffirmed in 2007 (ICAO, 2007). In the Balanced Approach, the ICAO has defined four key elements that can be used to achieve an effective reduction in aircraft noise without compromising safety standards (which have to take precedence over environmental protection):

- Noise reduction at source, i.e. the aircraft. This includes the use of quieter aircraft and the implementation of noise-reducing measures on the engines, wings and landing gear of existing aircraft fleets.

- Local measures in the vicinity of the airport. These include a land-use plan tailored to noise protection zones, passive noise control and noise based take-off and landing charges.

- Noise abatement operational procedures in the air and on the ground. The range of innovative flight procedures being trialled at various airports includes the continuous descent approach as well as satellite-supported approach procedures or 
measures that help to cut engine use on the ground. Both landing and take-off operations are critical from a noise point of view.

- Noise-based operating restrictions. These are any noise-related actions that limit or reduce an aircraft's access to an airport. They should not be used as a first resort, only after consideration of benefits gained from the other three elements, for example, noise quotas or curfews.

Following these ICAO (2007) key elements, we could classify the different noise mitigation opportunities that Capozzi et al. (2002) explore in their study, as shown in Table 2.

-Table 2

Various authors refer to real data from airports in their analysis. For example, Netjasov (2012) establishes a relationship between noise reduction measures used by 615 airports worldwide and the Balanced Approach categories.

Lijesen et al. (2010) constructed a bottom-up cost function, based on measures for noise reduction, such as alternative approach paths, fleet substitution and reduction of the number of flights for Amsterdam Airport. The conclusion from their analysis is that fleet substitution and alternative approach paths are viable ways to reduce noise, since reducing the number of flights can be too costly.

Another important issue is how noise is measured and in which units. A large variety of acoustic descriptors are used to describe aircraft noise (Ruijgrok, 2004). In order to select an aircraft noise descriptor, it is necessary to adjust to the issue being examined. However, the most common noise indices are expressed in terms of $\mathrm{dB}$. Noise policy and legislation are most often based on average noise levels: $\mathrm{L}_{\mathrm{eq}}$ (represents the time 
average of the total sound energy over a specified period) and its three special variants: $\mathrm{L}_{\mathrm{dn}}$ (day-night average sound level), $\mathrm{L}_{\mathrm{den}}$ (day-evening-night average sound level), and $\mathrm{L}_{\text {night }}$ (long term average sound level determined over all the night periods of a year). All of them are described in detail by Visser et al. (2008). Obviously, much information about traffic noise patterns and sound levels of individual vehicles is not taken into consideration using these average noise indices (Hume et al., 2012). In order to remediate this, regional indices are suitable to assess aircraft noise development around an airport: Zurich and Frankfurt airports are using the ZFI (Zurich Aircraft Noise Index) and FFI/FNI (Frankfurt Aircraft Noise Index/Frankfurt Night Index) indices respectively to measure noise impact (Schäffer et al., 2012; Schreckenberg et al., 2009). The ZFI is a noise effect index describing the integral effects of aircraft noise (annoyance and sleep disturbance) on the population in the vicinity of Zurich airport, integrating the considered noise effects to a single number valid for the whole airport (Schäffer et al., 2012). FFI describes the number of subjects highly annoyed by aircraft noise in areas within $\mathrm{L}_{\mathrm{dn}}$-contour $55 \mathrm{~dB}$ based on the 24 hours of the day. FNI solely serves to assess nocturnal air traffic by displaying the number of awakenings additionally induced by aircraft noise emitted between $10 \mathrm{pm}$ and $6 \mathrm{am}$, including regions where at least 0.5 additional aircraft noise induced awakenings are expected (Schreckenberg et al., 2009).

\section{NOISE REGULATION}

At a global level ICAO is responsible for developing standards for noise emissions from civil aircraft. ICAO requires Member States to adopt a balanced approach to noise management. 
At the EU level there is clear guidance provided by EU Directive 2002/30 for the establishment of rules and procedures with regard to the introduction of noise-related operating restrictions at community airports. The other key piece of European legislation in this area is EU Directive 2002/493 (Environment Noise Directive). This directive required Member States to create noise maps from all transport sources in urban areas by 2007 and to adopt action plans to manage noise by 2008 . The directive also aimed to harmonise methods for measuring noise across the EU. In December 2011 the European Commission launched its 'Better Airports Package' (European Commission, 2011). The package contained legislative proposals on aviation noise, among other issues. It was proposed to replace the Directive with a new EU regulation which would be directly applicable in each Member State without the need for Member States to implement the rules under local law. That was why the European Community adopted Regulation (EU) No. 598/2014 on the procedures concerning the introduction of noise-related operating restrictions. As restrictions also impact on air carriers from non-EU countries, the Regulation is compliant with international principles on noise management.

In the USA, the Federal Aviation Administration (FAA) has the authority and responsibility to control aircraft noise (FAA, 2016). Airport sponsors are primarily responsible for planning and implementing action designed to reduce the effect of noise on residents in the surrounding area. Such actions include noise abatement ground procedures and restrictions on airport use, among others. To accomplish this, airport sponsors must comply with the national programme for the review of airport noise and access restrictions under the Airport Noise and Capacity Act of 1990 (ANCA). The FAA regulation that implements ANCA is 14 Code of Federal Regulations (CFR) Part 161, Notice and Approval of Airport Noise and Access Restrictions. 
Girvin (2009), in her review, compares and contrasts aviation noise policies and noise abatement measures around the world. She finds that charges applied in different countries depend on aircraft noise categories, maximum per aircraft noise threshold above which aircraft pay noise surcharges per operation, time of operation, per operation, noise-limits per aircraft, or noise quotas.

Noise charges are often used with fees, depending on the aircraft noise registration category or certification levels (Genescà et al., 2013). Generally, the noise tax increases with aircraft noise, and sometimes with aircraft weight, since heavier aircraft also tend to be noisier. The application of discounts for quieter aircraft and noise surcharges for noisier aircraft is an encouragement to airlines to use more silent aircraft (Morrell \& Lu, 2000). Hsu \& Lin (2005) highlight that from the airport's perspective, the busier the airport, the higher the noise fee, charged per landing, to offset the environmental damage and compensate surrounding communities for the noise impact. However, airports must deal with the trade-off between environmental improvement and revenue losses, when determining noise charge policies.

In some countries, noise protection areas are defined. These are urban areas that should be not flown over due to noise minimization. The distance that should be kept from these protected areas depends not only on the aircraft type but also on the weather (since the wind has an enormous influence on noise propagation) (Schilke \& Feuerle, (2013).

\section{OPERATIONAL PROCEDURES FOR AVOIDING AIRCRAFT NOISE}

In an ideal world, an aircraft would take off, climb to its optimal cruising altitude, and 
stay up there as long as possible before beginning a constant, engines-idle descent until landing. In the real world, aircraft have to coordinate with ATC, which usually interrupts climbs and descents with level-offs and turns that force them to spend more time at lower altitudes (Laurenzo, 2006). The combination of low altitude and frequent thrust transients leads to significant noise impact on the ground (Coppenbarger, 2007).

Noise abatement operational procedures in use today cover both take-off and approach phases. The term Continuous Descent Approach (CDA) has been adopted to embrace the different techniques being applied to maximize operational efficiency while still addressing local airspace requirements and constraints during the approach of the aircraft to the airport. These operations have been variously known as, Continuous Descent Arrivals (Jackson et al., 2009), Optimized Profile Descents (McConnachie et al., 2015; Hughes et al., 2012), Tailored Arrivals (Pinkerton, 2013; Elmer et al., 2008), 3D Path Arrival Management (Tong et al., 2007) and Continuous Descent Operations (Thompson et al., 2013; Robinson \& Kamgarpour, 2010).

CDA (see Figure 1) allows aircraft to approach moderately dense terminal areas, eliminating the level altitude segments and their associated thrust transients at low altitude, while flying efficient, near-idle descent trajectories that save fuel, and reduce emissions and noise (Ren et al., 2011; Weitz et al., 2005). However, these procedures are not in use everywhere because effective implementation may be difficult since aircraft require special equipment and can have a negative impact on the airspace throughput and controller workload (Jackson, 2009; Reynolds et al., 2005). ATC lacks the required ground automation to provide separation assurance services during CDA operations. Thus, CDA is currently used in low traffic scenarios only (Kuenz et al., 2007; Tong et al., 2007). 
Research into terminal area operational improvements has predominantly focused on the descent phase of flight and improvements of operational performance using CDA, but few researches have considered the climb phase of flight. Noise Abatement Departure Procedures (NADPs) are the ICAO noise abatement take-off climb procedures defined in ICAO Doc 8168-OPS/611, Volume 1, Part 1, Section 7, Chapter 3 (ICAO, 2004). McConnachie et al. (2015) presented an approach for evaluating the current operational inefficiencies in the climb phase. Various references consider the Expedite Departure Path (EDP) component of the Center-TRACON Automation System (CTAS) in the USA (Capozzi et al., 2002). EDP is a decision support tool aimed at providing TRACON Traffic Management Coordinators (TMCs) with departure traffic loading and scheduling information, and radar controllers with advisories for tactical control of TRACON departure traffic. The benefits of EDP are a reduction in delay for departure operations, reduced fuel burn and reduced noise impact due to accelerated climb trajectories (Jung \& Isaacson, 2002).

Boeing (2016) provides a database of real noise and emissions restrictions from 654 airports all around the word. After analysing these data, we found that 517 airports have noise abatement procedures but only 72 airports have CDA procedures implemented or are in a trial stage of development, and just five have NADP ICAO's standard as their departure procedure. The others have procedures referring to arrival and/or departure trajectories, as well as recommended flying techniques or preferred use of certain runways.

\section{MONITORING, MODELLING \& SIMULATION FOR REDUCING NOISE}


We have found in the literature review that there is an important relationship between monitoring, modelling and simulation tools related to deal with the noise problem around airports. Monitoring is done in a real-time environment to measure the impact of noise. Modelling serves planning purposes and needs, from monitoring measures to validating the models developed. Simulation needs both monitoring and modelling in order to assist decision making for land-use planning, design of operational procedures, and the assessment of low-noise technology and vehicle concepts (Figure 2).

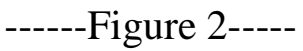

As mentioned before, the social impact of airport noise leads to the development of strict legislation globally. The legislation is based on noise monitoring, which usually combines information deriving from noise level meters and radars (Tarabini et al., 2014). This is why noise monitoring is considered to be the most important mechanism both for planning and noise management around airports (Asensio et al., 2010; 2011). It allows the measuring of sound level time history, identifying sound events and classifying the events produced by aircraft. Aircraft noise monitoring is carried out using a set of noise monitoring terminals (NMTs) that continuously measure the noise in the airport surroundings. Since the ultimate aim of aircraft noise monitoring is to help control the population's exposure to aircraft noise, ideally NMTs should be placed in urban areas. Urban centres, however, have high background noise levels, and the identification of aircraft specific noise is therefore a problem (Genescà et al., 2013). It is necessary then to consider the factors that can affect the uncertainty of the monitoring results. ISO 20906 deals with this by considering measuring instrumentation, residual sound, emission at the source, ground effect, etc.

Various studies in the literature deal with the monitoring problem. Asensio et al. (2009) 
propose a model that uses radar tracks to reduce the uncertainty to less than half of the ISO model. Asensio et al. (2010) designed a system that can detect aircraft sounds in real-time, so that its integration with a monitoring unit can improve aircraft detection rates during unattended measurements. Genescà et al. (2013) propose the use of an array of 12 microphones to measure direct aircraft noise, avoiding the effect of the ground reflections and urban background noise. In order to detect thrust reverse noise among other noise sources present in airports, Asensio et al. (2015) use a microphone array linked to a noise-monitoring unit, which enables sound pressure measurements to be transformed into sound power level estimations with good classification rates.

Since noise monitoring is essential to measure and control noise limits around airports, measures must be precise to be useful. Hence, the next step after a correct noise monitoring should be to validate the noise models developed.

Noise modelling is used to forecast current or future aircraft noise around airports (due to increases in flight volume or modification of flight paths) and to produce noise maps (Genescà, 2016; Sari et al., 2014). Different models, different implementations of the same noise calculation algorithms, different calculation methods, different data structure and different specific parameters to be adjusted by the user in order to represent the real situation, are in use worldwide. Krebs et al. (2008) present a new standardised test environment for aircraft noise calculation programmes.

The evaluation of noise in urban environments and in areas with main noise sources also represents a huge challenge, due to the high population density and the combination of different noise sources contributing to the overall acoustical environment. In particular, densely populated areas around large airports are exposed to noise from a combination of different sources. Sari et al. (2014) propose that noise 
generation and propagation are separately modelled according to basic physical effects.

Finally, fast but accurate simulation methods are required. Filippone \& Bertsch (2014) classify them as best practice and scientific prediction methodologies.

Firstly, best practice tools are usually based on fully empirical models derived from ground noise measurements. The Aviation Environmental Design Tool (AEDT) is the FAA's official method to calculate noise impact (until May 2015, it was the Integrated Noise Model (INM)). The AEDT is a software system that dynamically models aircraft performance in space and time to produce fuel burn, emissions and noise. It makes full flight gate-to-gate analyses possible for study sizes ranging from a single flight at an airport to scenarios at the regional, national, and global levels (Belle et al., 2015). The European Civil Aviation Conference (ECAC) proposes a similar method (using identical equations) to INM in their Document 29 (2005). Arntzen et al. (2014) updated these methods, supplying the noise model with an augmented ray tracing solution to predict the atmospheric propagation effects, rather than just using an empirical model.

Secondly, scientific predictions methodologies of aircraft noise play a large role in the policy making process and resulting regulations. These regulations are usually based on noise contours (a line on a map that represents equal levels of noise exposure) expressed in yearly averaged metrics. Noise contours around airports are used as planning and evaluation tools, and as a component of long-range efforts by local, regional or national authorities. Aircraft noise contour assessment is a complex procedure due to the different route schemes, procedures, aircraft and types of engine in operation around an airport (Zaporozhets \& Tokarev, 1998). The usage of a reliable, validated, and updated noise model is an essential step for producing accurate noise contours for the purposes of environmental noise analysis. But, noise maps are made mostly by calculations based 
on known and estimated parameters such as geographical data and the accurate accounting of noise source data. All these data cannot be readily available for the study areas. Therefore, assumptions and predictions are generally used to fill the gaps of model inputs (Mioduszewski et al., 2011).

However, a few approaches in the literature consider the trade-off between the different aspects needed to evaluate environmental impact, such as fuel burnt, noise exposure, and emissions produced, of future ATM concepts and procedures. Celikel et al. (2005) studied the combined use of airspace simulation, and environmental and economic tools, adding value to operational project evaluation.

\section{OPTIMIZATION ALGORITHMS FOR NOISE ABATEMENT}

Noise abatement procedures provide an effective means of achieving further reductions in the impact of aircraft noise on communities surrounding airports. Use of noise abatement procedures, however, has been limited by guidance and navigation considerations. The primary obstacle to the implementation of these procedures remains the inability of air traffic controllers to maintain manually the precise sequencing and spacing required for maximum take-off and landing rates in heavy traffic conditions. Thus, the introduction of automation that predicts the performance and noise impact of aircraft, and uses this information to assist the controller in determining and maintaining appropriate sequencing and spacing, is critical to the successful utilization of noise abatement procedures (Clarke, 2003).

Noise-aware decision support tools are needed so that the decision process for sequencing and scheduling terminal area and en route traffic as a means of increasing 
overall capacity and efficiency of operation, also includes consideration of noise exposure levels, particularly for the population within the immediate vicinity of the airport (Capozzi et al., 2002).

To our surprise, there is not a large amount of literature referring to the optimization of noise-scheduling. In Figure 3, we present the main studies found in the previous literature referring to the flight stages that can influence runway capacity.

Most research found in the literature considering optimization tools refers to flight path optimization (Visser, 2005; Salah \& Abdallah, 2012; Salah, 2013). Trajectories optimization considers avoiding built-up areas, topographical details, safety requirements and ATC requirements (Filippone, 2014).

It is possible, however, to find airport noise optimization and aircraft scheduling dating back to 1984. Frair (1984) formulated an optimization mathematical model whose objective is to minimize the measure of annoyance due to arriving and departing aircraft for a given airport, obtaining a $40 \%$ reduction in noise impacts.

Temme (2007) defines an interesting method to support the air traffic controller with noise abatement routes during real-time approach planning and guiding. The soundsource aircraft, the propagation medium atmosphere including actual meteorological conditions, a three dimensional model of the earth's surface, and the population distribution around an airport, are all taken into account for the noise propagation calculation.

Hebly \& Visser (2007) present a decision support system (DSS) for air traffic controllers for guiding arriving and departing traffic near airports in a safe and efficient 
manner, making use of the future concept of four-dimensional trajectory-based operations. While doing so, the system minimizes the negative environmental effects of the flight operations and manages their spatial allocation, both for individual movements and cumulative exposure. They formulate the problem as a Mixed Integer Linear Programming (MILP) with Constrained Position Shift (CPS) restrictions.

Prats et al. (2010) define a non-linear programing (NLP) problem for departure optimization that is solved by using a lexicographic multi-objective optimization technique. This approach allows the establishment of a hierarchical order among all different noise sensitive locations. However, the major drawback of this approach is the limitation in the number of noise sensitive locations to be considered, due to the exponential growth in computational cost.

The use of optimization tools for real-time aircraft guiding may lead to difficulties, because it requires delivering online results. Unlike Standard Instrument Departure (SID) routes, which follow fixed flight paths, arriving aircraft are guided flexibly by the aircraft controller with radar vectoring. A possible alternative is to reduce the amount of possible arrival trajectories by including the local airspace structure around the airport and taking the trajectory calculation rules of an arrival manager into account (Temme, 2007), then it is possible to reduce the number of possible flight paths significantly and to archive them together with a noise value - depending on population values - in a database. This way, the arrival manager has the possibility to take aircraft noise as well as safety, punctuality, and capacity constraints during the arrival sequencing generation into account.

An interesting and complete study has been undertaken by Zachary et al. (2010). They propose an optimization algorithm that explores the best selection of flight possibilities 
given to minimize noise and/or emissions by selecting available aircraft trajectories, schedules, operational procedures, e.g. time profiles of turbine power levels at take-off and climb, flap settings in take-offs and approaches, altitude variations in climb and approaches, take-off/landing runway displacements, and fleet composition, through a non-linear integer programming (NLIP) minimization problem.

\section{RESEARCH OPORTUNITIES}

The main approaches addressed today to reduce the impact of noise in the surrounding communities of airports, excluding impacting on land use and/or carrying sound insulation methods, consider operational procedures and regulatory restrictions. Airports must deal with the trade-off between environmental improvement and revenue losses when determining noise charge policies, as well as with the loss of capacity when fixing regulatory restrictions. The largest airports are those that have a greater population near them and also the ones that suffer from more congestion and delays, which results in more environmental impact.

Noise can be significantly reduced if the focus is set on developing optimal scheduling tools that avoid manoeuvres in the approach stage of the flight waiting for authorization to land, and departures are able to arrive at higher altitudes as fast as possible.

Making the most efficient use of the current infrastructure is an important part of the solution. A significant amount of research has been published for optimizing the scheduling of flights in airports. In this sense, Bennel et al. (2013) review the techniques and tools of operational research and management science that are used for scheduling aircraft landings and take-offs in order to optimize airport runway scheduling. The main solution techniques include dynamic programming, branch and 
bound, heuristics and meta-heuristics.

Noise restrictions are almost not present when developing these algorithms. We have found just one interesting perspective to include noise in scheduling optimization. Sölveling et al. (2011) studied runway scheduling optimization based on environmental $\left(\mathrm{CO}_{2}\right.$ and noise) impacts, finding that it might produce important savings for the stakeholders implied (society, airports and airlines). There is a large field of investigation yet to be developed in terms of optimization algorithms that take into account noise as a constraint or objective of research.

Hence, optimization algorithms that take into account noise constraints avoiding inefficient schedules should be developed and tested. Controllers need these tools to be able to maintain safety and efficiency but also to address noise and environmental issues.

In order to evaluate the optimization algorithms and models developed, it is also necessary to develop standardised calculation methods that use the same data as input in order to be able to compare the results in a consistent way. These calculation methods should consider not only the different noise sources but also be able to match noise predictions with measured data. Hence, validation standards is another topic that needs future research attention in order to develop tools that are really useful in the reduction of noise in airport surroundings.

\section{CONCLUSIONS}

Minimizing noise disturbance around airports is a task that needs the implications for various stakeholders to be considered: institutions, aircraft manufacturers, airlines and 
ATC. There is a real concern by authorities that can be seen in the recent legislations and official restrictions that have been imposed.

There is also a need to improve modelling-simulation-monitoring tools that take into account all the factors implied in the noise problem (weather, population affected, air traffic congestion, airport capacity, etc.). A standardised tool would be necessary, since existing programmes differ greatly in their calculation methods and in data structure, so it is very difficult to compare the results in a consistent way.

There is a large field of research in terms of optimization tools that support air traffic controllers to help them optimize the capacity of airports without breaking the noise abatement procedures established in the vicinity of airports. Designing online scheduling tools that consider noise restrictions has not yet been studied in depth.

Predictions confirm the growth of air traffic transport in the future, thus increasing the noise problem around airports. Operational procedures need to take into account the capacity of the airport in order not to decrease the acceptance ratio of departures and arrivals. Using ICAO standard procedures worldwide for noise mitigation would be an important improvement. There is a large field of research on optimization algorithms that could help controllers schedule airport operations by considering noise restrictions.

\section{ACKNOWLEDGEMENTS}

This study was funded by the Ministry of Economy and Finance DP12013-41469-P and the European Regional Development Fund (ERDF). The authors are grateful to the anonymous referees for their valuable comments and suggestions that have contributed to improving the quality of this paper. 


\section{REFERENCES}

Abeyratne, R., 2002. Some recent developments in aviation and environmental protection regulation. Environmental Policy and Law 32(1), 32-40.

Airbus 2014. Global Market Forecast 2015-2034. Available online at www.airbus.com/company/market/forecast/ (accessed $13^{\text {th }}$ March 2016).

$\begin{array}{llll}\text { ANCA (1990). } & \text { Retrieved }\end{array}$ https://www.lawa.org/uploadedFiles/LAX/noise/Part161/PDF/Airport_Noise_and_Capa city_Act_of_1990.pdf (accessed 12 $2^{\text {th }}$ September 2016).

Arntzen, M., Simons, D.G., 2014. Modeling and synthesis of aircraft flyover noise. Applied Acoustics 84(1), 99-106.

Arntzen, M., Heblij, S.J., Simons, D.G., 2014. Weather-dependent airport noise contour prediction concept based on ray tracing. Journal of Aircraft 51(5), 1351-1359.

Asensio, C., Pavón, I., Ruiz, M., Pagán, R., Recuero, M., 2009. Aircrafts' taxi noise. Sound power level and directivity frequency band results. Applied Acoustics 70(7), 986-1008.

Asensio, C., Ruiz, M., Recuero, M., 2010. Real-time aircraft noise likeness detector. Applied Acoustics 71(6), 539-545.

Asensio, C., Recuero, M., Ruiz, M., 2011. Aircraft noise-monitoring according to ISO 20906. Evaluation of uncertainty derived from the classification and identification of aircraft noise events. Applied Acoustics 73(1), 209-217.

Asensio, C., Ruiz, M., Recuero, M., Moschioni, G., Tarabini, M., 2015. A novel intelligent instrument for the detection and monitoring of thrust reverse noise at airports. International Measurement Confederation (IMEKO) 1(1), 5-10.

ATAG 2014. www.atag.org, (accessed $13^{\text {th }}$ April 2016). 
Belle, A., McConnachie, D., Bonnefoy, P., 2015. A methodology for environmental and energy assessment of operational improvements. 11th USA/Europe Air Traffic Management Research and Development Seminar, ATM 2015.

Bennell, J.A., Mesgarpour, M., Potts, C.N., 2013. Airport runway scheduling. Annals of Operations Research 204(1), 249-270.

Bertsimas, D., Lulli, G., Odoni, A., 2011. An integer optimization approach to largescale air traffic flow management. Operations Research 59(1), 211-227.

Boeing Database (2016). http://www.boeing.com/commercial/noise/list.page. (accessed $12^{\text {th }}$ September 2016).

Capozzi, B., Augustine, S., Thompson, T.R., Robinson, J.E., 2002. An initial assessment of benefits for noise-aware decision-support tools. AIAA's Aircraft Technology, Integration, and Operations (ATIO) 2002 Technical Forum, Los Angeles, CA.

Celikel, A., Hustache, J.-C.C., De Lepinay, I., Martin, K., Melrose, A., 2005. Environmental tradeoffs assessment around airports. 6th USA/Europe Air Traffic Management Research and Development Seminar, ATM 2005, 254-264.

Clarke, J.P., 2003. The role of advanced air traffic management in reducing the impact of aircraft noise and enabling aviation growth. Journal of Air Transport Management 9(3), 161-165.

Coppenbarger, R., 2007. Oceanic tailored arrivals, Boeing. Tailored Arrivals Symposium. Seattle, WA.

Creswell, J.W., 2013. Review of the Literature. Research Design. Qualitative, Quantitative, and Mixed Method Approaches (4th ed.). Thousand Oaks, CA: Sage Publications 
Denyer, D., Tranfield, D., 2009. Producing a systematic review. In D.A. Buchanan \& A. Bryman (Eds.), The Sage handbook of organizational research methods (pp. 671-689). London: Sage Publications Ltd.

Elmer, K.R., Mead, R., Bailey, L., Cornell, B., Follet, J., Lanier, R.C., 2008. Operational implementation of Tailored Arrivals at SFO and expected environmental benefits. In 8th AIAA Aviation Technology, Integration and Operations (ATIO) Conference.

EU Directive 2002/493. Environment Noise Directive.

EU Directive 2002/30. Establishment of rules and procedures with regard to the introduction of noise-related operating restrictions at Community airports.

European Civil Aviation Conference (ECAC). https://www.ecac-ceac.org/ (accessed $12^{\text {th }}$ September 2016).

European Commission 2011. Better Airports Package.

FAA 2016. www.faa.gov (accessed $12^{\text {th }}$ September 2016).

Filippone, A., 2014. Aircraft noise prediction. Progress in Aerospace Science 68(1), 2763.

Filippone, A., Bertsch, L., 2014. Comparison of aircraft noise models with flyover data, Journal of Aircraft 51(3), 1043-1047.

Flores-Fillol, R., 2010. Congested hubs. Transportation Research-B 44, 358-370.

Frair, L., 1984. Airport noise modelling and aircraft scheduling so as to minimize community annoyance. Applied Mathematical Modelling 8, 271-281.

Ganic, E.M., Netjasov, F., Babic, O., 2015. Analysis of noise abatement measures on European airports. Applied Acoustics 92, 115-123. 
Genescà, M., Romeu, J., Arcos, R., Martín, S., 2013. Measurement of aircraft noise in a high background noise environment using a microphone array. Transportation Research Part D: Transport and Environment 18, 70-77.

Genescà, M., 2016. Directional monitoring terminal for aircraft noise. Journal of Sound and Vibration 374, 77-91.

Girvin, R., 2009. Aircraft noise-abatement and mitigation strategies. Journal of Air Transport Management 15(1), 14-22.

Hebly, S.J., Visser, H.G., 2007. Air traffic control decision support for integrated community noise management. 7th AIAA Aviation Technology, Integration, and Operations Conference 1, 276-286.

Hsu, C.I., Lin, P.H., 2005. Performance assessment for airport noise charge policies and airline network adjustment response. Transportation Research Part D: Transport and Environment 10(4), 281-304.

I

Hughes, K.K., Wu, C.Y., Lamp, J.L., Coleman, A.G., Adili, P., Dhanoya, S.K., White, K.P., 2012. Optimizing Airport Arrival Operations: A Systems Engineering Analysis of Washington Dulles International Airport. In Proceedings of the 2012 IEEE Systems and Information Engineering Design Symposium, 145-149. Charlottesville: IEEE.

Hume K.I., Brink M., Basner M., 2012. Effects of environmental noise on sleep. Noise Health 14, 297-302.

ICAO 2001. Part V, Annex 16 to the Chicago Convention. ICAO Assembly Resolution A37-18, Appendix C.

ICAO 2004. Doc 8168-OPS/611. Procedures for Air Navigation Services - Aircraft Operations, Volume 1 - Flight Procedures. 
ICAO 2007. Doc 9828. Guidance on the Balanced Approach to Aircraft Noise Management.

ICAO 2013. $38^{\text {th }} \quad$ ICAO General Assembly Resolutions. http://www.icao.int/Meetings/a38/Pages/resolutions.aspx

Ignaccolo, M., 2000. Environmental capacity: Noise pollution at Catania-Fontanarossa international airport. Journal of Air Transport Management 6(4), 91-199.

ISO 20906:2009. Acoustics - unattended monitoring of aircraft sound in the vicinity of airports.

Jackson, M.R.C., 2009. CDA with RTA in a mixed environment. AIAA/IEEE Digital Avionics Systems Conference, 1-10. doi:10.1109/DASC.2009.5347545.

Jackson, M.R.C., Gonda, J., Mead, R., Saccone, G., 2009. The 4D trajectory data link (4DTRAD) service - Closing the loop for air traffic control. 2009 Integrated Communications, Navigation and Surveillance Conference, 1-10. doi:10.1109/ICNSURV.2009.5172860.

Janssen S.A., Centen M.R., Vos H., Van Kamp I., 2014. The effect of the number of aircraft noise events on sleep quality. Applied Acoustics 84(1), 9-16.

Jung, Y.C., Isaacson, D.R., 2002. Design concept and development plan of the expedite departure path (EDP). AIAA's Aircraft Technology, Integration, and Operations (ATIO) 2002 Technical Forum, American Institute of Aeronautics and Astronautics, 110.

Krebs, W., Balmer, M., Lobsiger, E., 2008. A standardised test environment to compare aircraft noise calculation programs. Applied Acoustics 69(11), 1096-1100.

Kuenz, A., Mollwitz, V., Korn, B., Guidance, F., 2007. Green trajectories in high traffic TMAs. Digital Avionics Systems Conference, 1-11. 
Laurenzo, R., 2006. Hushing the roar of air traffic growth. Aerospace America 1, 38-42.

Lijesen, M., Van der Straaten, W., Dekkers, J., van Elk, R., Blokdijk, J., 2010. How much noise reduction at airports?, Transportation Research Part D: Transport and Environment 15(1), 51-59.

McConnachie, D., Bonnefoy, P., Belle, A., 2015. Investigating benefits from continuous climb operating concepts in the national airspace system: Data and simulation analysis of operational and environmental benefits and impacts. 11th USA/Europe Air Traffic Management Research and Development Seminar, ATM 2015.

Mioduszewski, P., Ejsmont, J.A., Grabowski, J., Karpiński, D., 2011. Noise map validation by continuous noise monitoring. Applied Acoustics 72(8), 582-589.

Morrell, P., Lu, C.H.Y., 2000. Aircraft noise social cost and charge mechanisms - a case study of Amsterdam Airport Schiphol. Transportation Research Part D: Transport and Environment 5(4), 305-320.

Netjasov, F., 2012. Contemporary measures for noise reduction in airport surroundings. Applied Acoustics 73, 1076-1085.

Ozkurt, N., Sari, D., Akdag, A., Kutukoglu, M., Gurarslan, A., 2014. Modeling of noise pollution and estimated human exposure around Istanbul Atatürk Airport in Turkey. Science of the Total Environment 482-483(1), 486-492.

Pinkerton, S., 2013. Arrival Procedures- From Standard to Tailored Arrivals. Oceanic and Offshore Operations Support Group. FAA.

Prats, X., Puig, V., Quevedo, J., Nejjari, F., 2010. Lexicographic optimisation for optimal departure aircraft trajectories. Aerospace Science and Technology 14(1), 26-37.

Regulation EU No. 598/2014. Establishment of rules and procedures with regard to the introduction of noise-related operating restrictions at Union airports within a Balanced Approach and repealing Directive 2002/30/EC. 
Ren, L., Reynolds, T.G., Clarke, J.P.B., Hooper, D.A., Parton, G.A., Dore, A.J., 2011. Meteorological influences on the design of advanced aircraft approach procedures for reduced environmental impacts. Meteorological Applications 18(1), 40-59.

Reynolds, H.J.D., Reynolds, T.G., Hansman, R.J., 2005. Human factors implications of Continuous Descent Approach procedures for noise abatement in air traffic control. Proceedings of the 6th USA/Europe Air Traffic Management Research and Development Seminar, 374-383.

Robinson, J., Kamgarpour, M., 2010. Benefits of Continuous Descent Operations in High-Density Terminal Airspace Under Scheduling Constraints. 10th AIAA Aviation Technology, Integration, and Operations (ATIO) Conference, 1-21.

Ruijgrok, G.J.J., 2004. Elements of Aviation Acoustics. Delft University Press, Delft, The Netherlands.

Salah, K., 2013. Applied methods validating aircraft flight path optimization. theoretical and experimental considerations. Applied Mathematical Sciences 7(45), 2209-2228.

Salah, K., 2014. Environmental impact reduction of commercial aircraft around airports. Less noise and less fuel consumption. European Transport Research Review 6(1), 7184.

Salah, K., Abdallah, L., 2012. Optimization approaches of aircraft flight path reducing noise: Comparison of modeling methods. Applied Acoustics 73(4), 291-301.

Sari, D., Ozkurt, N., Akdag, A., Kutukoglu, M., Gurarslan, A., 2014. Measuring the levels of noise at the İstanbul Atatürk Airport and comparisons with model simulations. The Science of the Total Environment. doi:10.1016/j.scitotenv.2013.07.091.

Schäffer, B., Thomann, G., Huber, P., Brink, M., Plüss, S., Hofmann, R., 2012. Zurich Aircraft Noise Index : An Index for the Assessment and Analysis of the Effects of Aircraft Noise on the Population. Acta Acustica United with Acustica, 98, 505-519. 
Schilke, C., Feuerle, T., 2013. Development of a database for strategic route planning considering noise protection areas and meteorological conditions, 2013 IEEE/AIAA $32^{\text {nd }}$ Digital Avionics Systems Conference (DASC), East Syracuse, NY, 5B3-1-5B3-13. doi: 10.1109/DASC.2013.6712600

Schneider, O., Kreth, S., Bertsch, L., 2010. Towards a quiet short take-off and landing transportation system: Concept evaluation and ATM integration. International Powered Lift Conference 2010, 481-492.

Schmidt, C.W., 2005. Noise that annoys: regulating unwanted sound, Environmental Health Perspectives 113(1), A42-A44.

Schreckenberg, D., Thomann, G., Basner, M., 2009. FFI and FNI - Two effect based aircraft noise indices at Frankfurt airport. Paper 0412 in Proceedings of Euronoise 2009, 1-10. EURONOISE 2009, Edinburgh, Scotland.

SESAR 2016. www.sesarju.eu/ (accessed $13^{\text {th }}$ March 2016).

Sölveling, G., Solak, S., Clarke, J.P.B., Johnson, E.L., 2011. Scheduling of runway operations for reduced environmental impact, Transportation Research Part D: Transport and Environment 16(2), 110-120.

Tarabini, M., Moschioni, G., Asensio, C., Bianchi, D., Saggin, B., 2014. Unattended acoustic events classification at the vicinity of airports, Applied Acoustics 84(1), 91-98.

Temme, M., 2007. Real-time aircraft noise prediction for trajectory based arrival manager. 25th Congress of the International Council of the Aeronautical Sciences 2006, 7, 4039-4045.

Thompson, T., Miller, B., Murphy, C., Augustine, S., White, T., Souihi, S., 2013. Environmental impacts of continuous-descent operations in Paris and New York Regions. In Proceedings of the 10th USA/Europe Air Traffic Management Research and Development Seminar, ATM 2013, 1-22. 
Tong, K.O., Schoemig, E.G., Boyle, D.A., Scharl, J., Haraldsdottir, A., 2007. Descent profile options for continuous descent arrival procedures within 3D path concept. AIAA/IEEE Digital Avionics Systems Conference, 1-11.

Upham, P., Thomas, C., Gillingwater, D., Raper, D., 2003. Environmental capacity and airport operations: Current issues and future prospects. Journal of Air Transport Management 9(3), 145-152.

Visser, H.G., 2005. Generic and site-specific criteria in the optimization of noise abatement trajectories. Transportation Research Part D: Transport and Environment, 10(5), 405-419.

Visser, H., Hebly, S., Wijnen, R., 2008. Improving the management of the environmental impact of airport operations. In New Transportation Research Progress, chapter 1, 1-65, Nova Science Publishers, Amsterdam.

Vogiatzis, K., 2012. Airport environmental noise mapping and land use management as an environmental protection action policy tool. The case of the Larnaka International Airport (Cyprus). Science of the Total Environment, 424, 162-173.

Weitz, L.A., Hurtado, J.E., Texas, A., Station, C., Barmore, B.E., Langley, N., 2005. An analysis of merging and spacing operations with continuous descent approaches. 24th Digital Avionics Systems Conference, 1-11. doi:10.1109/DASC.2005.1563325

Zachary, D.S., Gervais, J., Leopold, U., 2010. Multi-impact optimization to reduce aviation noise and emissions. Transportation Research Part D: Transport and Environment 15(2), 82-93.

Zaporozhets, O.I., Tokarev, V.I., 1998. Aircraft noise modelling for environmental assessment around airports. Applied Acoustics 55(2), 99-127. 


\begin{tabular}{|c|c|}
\hline NextGen (USA) & SESAR $($ EU) \\
\hline Climate & Global Emissions \\
\hline Air quality & Local Emissions \\
\hline Aircraft noise & Noise \\
\hline Water & \\
\hline Energy & \\
\hline
\end{tabular}

Table 1. NextGen (FAA, 2016) vs. SESAR (2016) environmental objectives 


\begin{tabular}{|c|c|}
\hline ICAO Balanced Approach (2007) & Capozzi et al. (2002) \\
\hline 1. Noise reduction at source & - \\
\hline $\begin{array}{l}\text { 2. Local measures in the vicinity of } \\
\text { the airport }\end{array}$ & - \\
\hline $\begin{array}{l}\text { 3. Noise abatement operational } \\
\text { procedures in the air and on the } \\
\text { ground }\end{array}$ & $\begin{array}{l}\text { Noise-sensitive ATM approach procedures: } \\
\text { - } \quad \text { Avoid dive and drive } \\
\text { - } \quad \text { Base leg extension into noise sensitive } \\
\text { areas } \\
\text { - } \\
\text { Nide-step approaches } \\
\text { Noise-sensitive ATM departures procedures: } \\
\text { Direct climb-to-cruise } \\
\text { Route tracking: } \\
\text { - } \quad \text { Stay in precise route corridor } \\
\text { - } \quad \text { Follow routes over low population areas } \\
\text { - } \quad \text { Avoid shortcutting }\end{array}$ \\
\hline 4. Noise-based operating restrictions & $\begin{array}{l}\text { Runway/route selection: } \\
-\quad \text { Fan across region } \\
-\quad \text { Routing older aircraft to less noise- } \\
\text { sensitive runways } \\
\text { - } \quad \text { Increase the usage of noise-preferred } \\
\text { runways } \\
\text { Airport interactions within a Terminal Radar } \\
\text { Approach Control (TRACON), modifying } \\
\text { existing procedures to consider noise } \\
\text { Night time operations: } \\
\text { - } \quad \text { Extend procedures to higher traffic } \\
\text { levels } \\
\text { - Improve efficiency so that night time } \\
\text { operations can be initiated on time }\end{array}$ \\
\hline
\end{tabular}

Table 2. Capozzi et al. (2002) vs. ICAO Balanced Approach (2007) noise mitigation approaches 


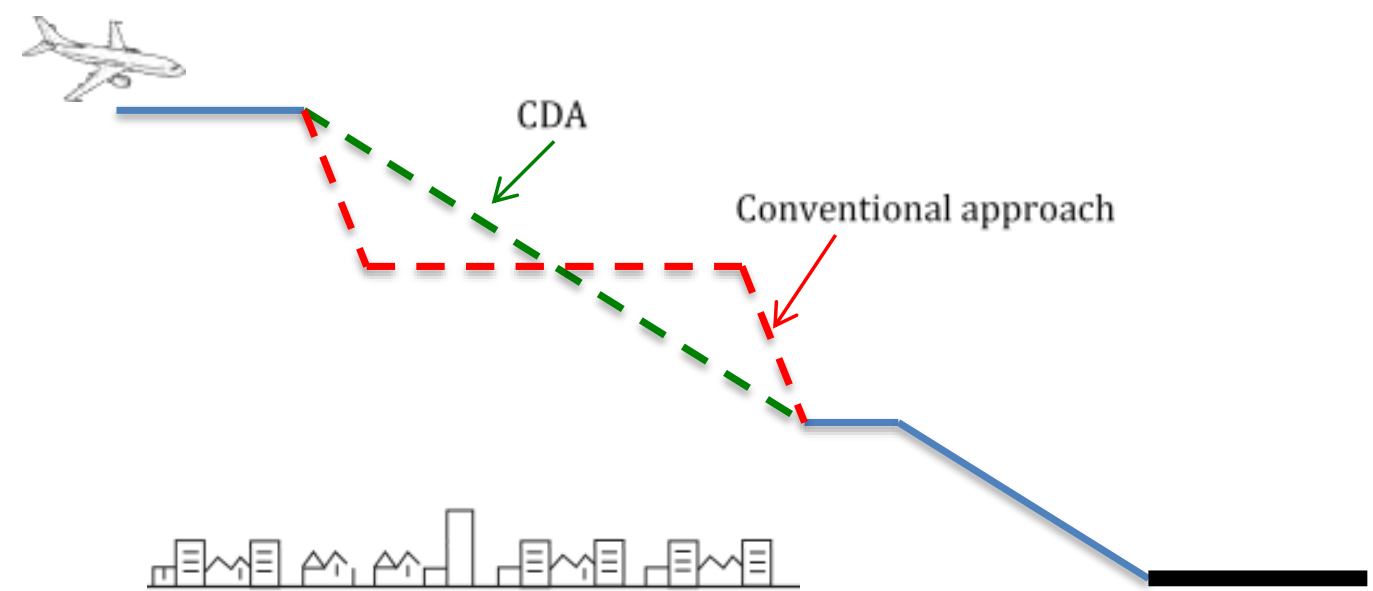

Figure 1. CDA vs. conventional approach 




Figure 2. Monitoring - Modelling - Simulation relationship 


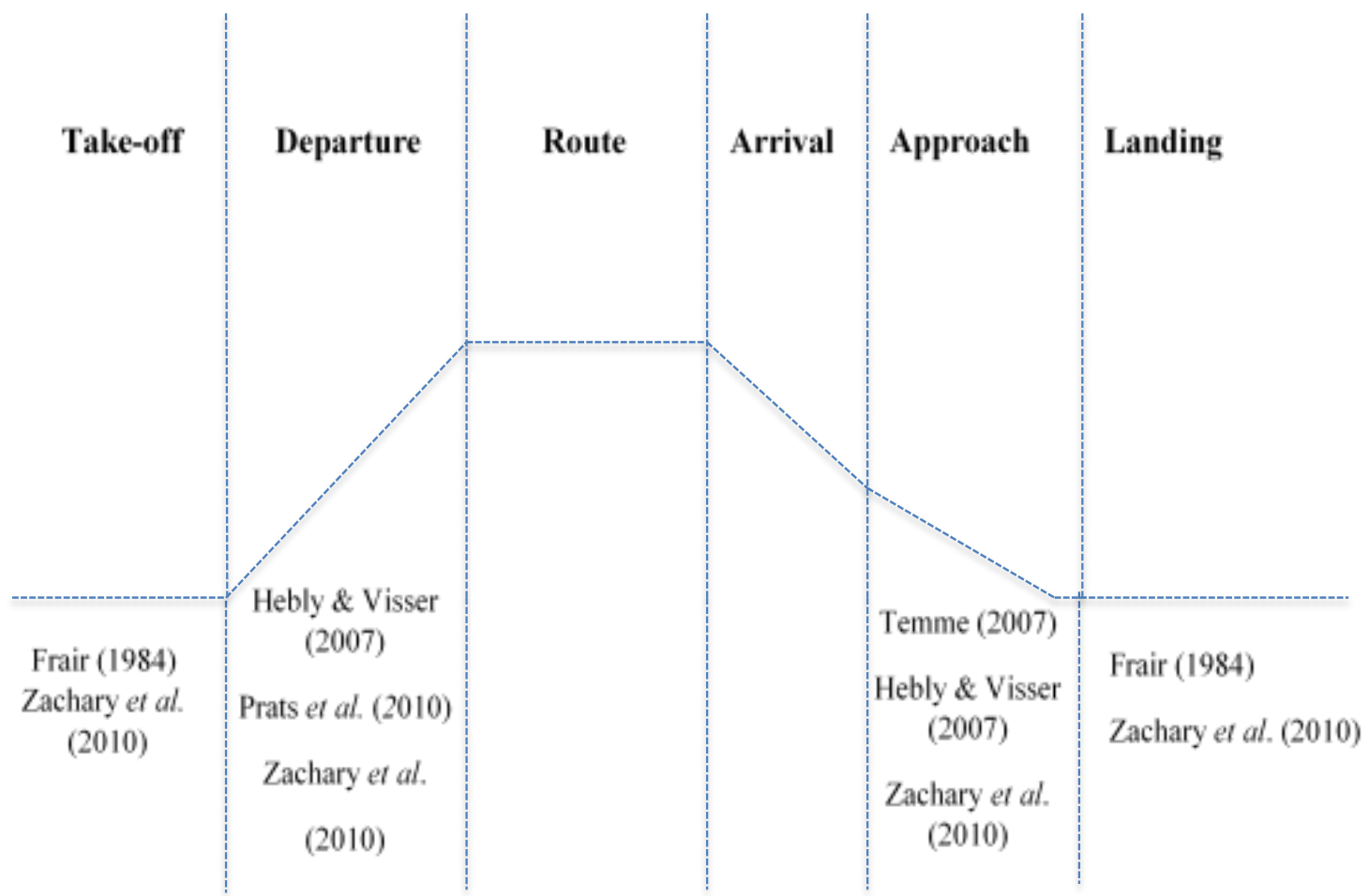

Figure 3. Optimization algorithms depending on the flight stage 